\title{
POLITICAL INSTITUTIONS AND ECONOMIC GROWTH*
}

\author{
Laura Marsiliani \\ University of Durham
}

\author{
Thomas I. Renström \\ University of Durham and CEPR
}

October 2004

We analyze the impact of micro-founded political institutions on economic growth in an overlappinggenerations economy, where individuals differ in preferences over a public good (as well as in age). Labour- and capital taxes finance the public good and a public input. The benchmark institution is a parliament, where all decisions are taken. Party entry, parliamentary composition, coalition formation, and bargaining are endogenous. We compare this constitution to separation of powers, where a spending minister (elected in parliament or appointed by the largest party). Separation of powers tend to yield lower growth, mainly due to the occurrence of production inefficiency.

Keywords: Comparative politics, voting, bargaining, taxation, endogenous growth, overlapping generations.

JEL classification: D70, E21, E62, H20, H55.

Correspondence to: T.I. Renström, Department of Economics and Finance, University of Durham, 2326 Old Elvet, Durham DH1 3HY, UK, (Fax: +44-191-334 6369).

Email t.i.renstrom@durham.ac.uk

http://www.dur.ac.uk/t.i.renstrom/

* We wish to thank Piergiuseppe Fortunato, participants to the Economic Growth and Distribution conference, Lucca, and seminar participants at University of Southampton for useful comments. 


\section{INTRODUCTION}

A recent interest in political economy is about how political institutions, for example parliamentary or congressional systems (and different electoral rules), influence economic policy decisions and economic performance.

Earlier work on the role of political institutions is by Persson, Roland and Tabellini (2000) which presents a theory of how a parliamentary system is more able to enhance public spending than a congressional/presidential system. This finding is corroborated by empirical studies (Persson and Tabellini (2003 and 2004)). More recently, Persson (2004) find empirical evidence for parliamentary systems and proportional electoral rules to promote economic growth. Further evidence on the impact of political institutions and economic development can be found in Hall and Jones (1999), Acemoglu, Johnson and Robinson (2001), Glaeser et al. (2004), Rodrik, Subramanian and Trebbi (2004).

However, as Persson (2004) points out "this research has no more than scratched the surface when it comes to structural policies related to long-run economic performances". Indeed to our knowledge there is no theoretical model which provides a micro-founded theory of how constitutional rules work and impact on economic growth. ${ }^{1}$

This paper intends to contribute to the existing literature on political institutions and economic performance by presenting a micro-founded theory of constitutions influence economic growth. In particular we analyse the consequences of separation of powers (intended to capture one aspect of a congressional system).

We analyze political-economic equilibrium economic growth when growth depends

\footnotetext{
1 The theoretical political-economy literature on economic growth sofar has applied the median-voter model and the focus have been on the income-inequality dimension. The idea put forth by Persson and Tabellini (1994) was that unequal societies (in terms of income or income-earning abilities) grow at as slower rate, due to the disincentives caused by distortionary taxation. If the median voter is poorer relative to the average, she finds it optimal to impose a larger tax. Empirically the findings are mixed, however.
} 
on two sources: public spending in production $^{2}$ and private capital accumulation. Public spending in production is the choice of the government. Private capital accumulation depends on the incentives to accumulate capital, and those incentives are functions of government tax policy.

We build a model where individuals differ in their tax bases (due to differences in age) and in their preferences over public goods. There will be a conflict of interest when choosing productive public spending (which comes at the expense of consumption public spending, public goods). There will also be a conflict of interest over which tax base to tax more (labour or capital). Since individuals differ along two dimensions (age and preferences) and policy is multidimensional (three dimensions) we will in general not have a Condorcet winning policy triple. We overcome this problem by model policy through (micro-founded) parliamentary decision making. We also make constitutional experiments and are able to identify growth promoting constitutions.

Our baseline institution is a parliament, which is modelled differently from the existing literature on legislatures [see Persson and Tabellini (2000) and in particular (2004)]. ${ }^{3}$

We assume that policy proposals can be negotiated upon, by modelling a simple bargaining game. We also introduce a further stage in endogenising the composition of the legislature through proportional voting. ${ }^{4}$ This is important, since in this way we allow the electorate to

\footnotetext{
2 Here we follow Turnovsky and Fisher (1995).

3 The common feature of those models is the way in which legislators reach an agreement through legislative bargaining (as in Baron and Ferejohn (1989)). A randomly selected legislator makes a take-it-or-leave-it proposal to the others. Characteristic about those models are that a winning policy proposal is some individual's ideal point (i.e. most preferred proposal). This implies that the winning policy is "confiscatory" in the sense that it leaves some individuals with no consumption at all.

4 Earlier works on the role of alternative electoral rules are Lizzeri and Persico (2001), Milesi-Ferretti, Perotti and Rostagno (2002), Persson and Tabellini (1999) and (2000), and Persson, Roland and Tabellini (2003). We do not consider majoritarian in this paper, but leave alternative electoral rules for future research.
} 
vote strategically and potentially neutralizing constitutional changes by altering the representation in the legislature.

The main results are as follows. If population growth is positive, the largest party in parliament consists of old with strong preferences for the public good. The politicalequilibrium coalition is between the largest party and a party consisting of young with weak preferences for the public good. Economic growth is larger because the young age group (though being divided) has larger influence. If there is negative population growth the largest party consists of young with strong preferences for the public goods. The coalition is between the largest party and a party consisting of old with weak preferences for the public good. Economic growth is lower.

The paper proceeds in analyzing the sensitivity of constitutional rules to the political equilibrium, in particular separation of powers. Here a spending decision maker is either elected in parliament or appointed by the largest party. It turns out that if population growth is negative, then economic growth is lower under separation of powers (and even lower if the spending minister is elected in parliament). If population growth is positive, then there is a possibility that separation of powers leads to higher growth (in particular if the spending minister is elected). The analysis suggests that the underlying distribution (in terms of demographics, or equivalently in our case, factor ownership) is an important factor in choosing constitutional framework. Also, for future empirical work it is important to control for the distribution.

The rest of the paper is structured as follows. In section 2 the overlapping-generations economy is introduced, the assumptions are formalised, and the economic equilibrium is 
solved for. In section 3 we present the political rules that make up our constitutions and solve for the political-economic equilibrium under the benchmark constitution. Section 4 deals with the constitutional experiment of separation of powers. In section 5 we analyse consequences for economic growth, and section 6 concludes.

\section{THE ECONOMY}

Individuals live for two periods, consuming both as young and as old, but work only when young. They have preferences over period-one consumption, period-two consumption, and period-one and period-two provision of public goods. Individuals within each age group differ in preferences over public goods. For simplicity we assume that they are of two types. In period one individual $i$ born at $t$ supplies one unit of labour (inelastically) on the market and consume $c_{t}^{i t}$ units of the only consumption good. ${ }^{5}$ She is paid $\omega_{t}$ per unit of supplied labour and she saves $k_{t+1}^{i t}$ for the next period. Let $\tau_{t}^{l}$ and $\tau_{t}^{k}$ denote the wage-income tax rate and the capital-income tax rate respectively. It is convenient to define the after-tax prices as $\mathrm{P}_{t} \equiv(1$ $\left.\tau_{t}^{k}\right) R_{t}$ and $\omega_{t} \equiv\left(1-\tau_{t}^{l}\right) w_{t}$. In period two she receives after-tax return, $\mathrm{P}_{t+1}$, on her savings all of which is used for consumption $c^{i t}{ }_{t+1}$. The period-one and period-two per-capita consumption of the public good (equal for all individuals) are denoted $g_{t}$ and $g_{t+1}$ respectively. The government uses the tax receipts for public goods provision as well as provision of public infrastructure, $z_{t}$.

\footnotetext{
5 For the preferences we are going to work with (Cobb-Douglas), nothing changes if labour supply was elastic. The income and substitution effects on labour would cancel, and labour supply would just be a constant (provided the after-tax wage is positive).
} 


\subsection{Assumptions}

\section{A1 Population}

The size of generation $t$ is denoted $N_{t}$, and grows (declines) at a constant rate $n>(<) 0$.

Within each generation individuals are endowed with either low taste, $\theta^{l}$, or high taste, $\theta^{h}$, for the environment. The fraction of total population endowed with low (=no) taste for the environment $\left(\theta^{l}=0\right)$ is denoted $\gamma$, and is constant over time.

\section{A2 Individual Preferences}

For analytical tractability the utility function is assumed to be of the form

$$
U^{i t}(\cdot)=c_{t}^{i t}\left(c_{t+1}^{i t}\right)^{\beta}\left(g_{t}\right)^{\epsilon^{i}}\left(g_{t+1}\right)^{\beta \epsilon^{i}}
$$

where the parameters $\beta$ and $\varepsilon^{i}$ are positive.

\section{A3 Individuals' Constraints}

The individual budget constraints are

$$
\begin{gathered}
c_{t}^{i t}+k_{t+1}^{i t}=\omega_{t} \\
c_{t+1}^{i t}=\mathrm{P}_{t+1} k_{t+1}^{i t}
\end{gathered}
$$

\section{A4 Production}

Production is a function of capital and labour, as well as a productivity enhancing factor, $Z_{t}$, provided by the government. ${ }^{6}$ We assume congestion in this factor so only its per-capita level, $z_{t}=Z_{t} / N_{t}$, augments productivity. This factor eventually produces long-run growth. For simplicity we assume that technology is Cobb-Douglas:

\footnotetext{
6 Here we follow Turnovsky and Fisher (1995).
} 


$$
Y_{t}=A K_{t}^{\alpha}\left(z_{t} N_{t}\right)^{1-\alpha}
$$

\section{A5 Government's Constraint}

The tax receipts at time $t$ is fully used for provision of infrastructure and of the public good

$$
G_{t}+Z_{t}=Y_{t}-P_{t} K_{t}-\omega_{t} N_{t}
$$

\section{A6 Representative democracy}

\section{Bench mark constitution}

Economic policy at time $t$ (the tax rates $\tau_{t}^{l}, \tau_{t}^{k}$, and the public production input, $Z_{t}$, and consequently the public goods level) is determined by majority vote in parliament. A proposal may be worked out by one party if in majority, or by negotiations among two or more parties in parliament, if no single party has majority. Only the party with most seats may choose coalition partner(s), and only once. If no proposal is worked out, parliament dissolves and there is no government for one period. Each individual type may constitute a party, and members are only of the same type. Individual citizens vote on parties that participate in the election. Prior to the voting stage parties decide whether to enter (costlessly) or not. The number of seats obtained in parliament is proportional to the number of votes.

\section{Separation of powers (independent regulator)}

As bench mark constitution, except that prior to coalition formation in parliament, a spending minister is chosen (either through a majority vote in parliament, or through appointment by the largest party). The spending minister takes the decision on the level of the public infrastructure and public goods provision after the parliament has chosen the tax rates. 


\subsection{Economic Equilibrium}

In this section the individual and aggregate economic behaviour are solved for, given any arbitrary sequences of tax rates and public expenditure.

By profit maximisation the before-tax prices (the interest rate and the wage rate) are given by

$$
R_{t}=\alpha y_{t}(1+n) / k_{t} \quad(6) \quad w_{t}=(1-\alpha) y_{t}
$$

respectively, where

$$
y_{t}=A\left(\frac{k_{t}}{1+n}\right)^{1-\alpha} z_{t}^{1-\alpha}
$$

Maximisation of (1) subject to (2)-(3) gives the individuals' decision rules

$$
c_{t}^{i t}=\frac{\omega_{t}}{1+\beta} \quad \text { (9) } \quad k_{t+1}^{i t}=\frac{\beta \omega_{t}}{1+\beta} \quad(10) \quad c_{t+1}^{i t}=\frac{\beta P_{t+1} \omega_{t}}{1+\beta}
$$

and indirect utility (up to a multiplicative constant)

$$
V_{t}^{i t}=\left(\omega_{t}\right)^{1+\beta}\left(\boldsymbol{P}_{t+1}\right)^{\beta}\left(\boldsymbol{g}_{t}\right)^{e^{i}}\left(\boldsymbol{g}_{t+1}\right)^{\beta \mathrm{e}^{i}}
$$

An old individual's indirect utility is

$$
V_{t}^{j t-1}=\left(\boldsymbol{P}_{t} k_{t}\right)^{\beta}\left(\boldsymbol{g}_{t}\right)^{\beta e^{j}}
$$

Finally, the government's budget constraint in per-capita form may be written as

$$
g_{t}=G_{t} / N_{t}=\pi_{t} y_{t}-z_{t}
$$

where

$$
\pi_{t} \equiv 1-\alpha\left(1-\tau_{t}^{k}\right)-(1-\alpha)\left(1-\tau_{t}^{l}\right)
$$


Anticipating that $z_{t}$ will be chosen as a fraction of GDP, i.e.

$$
z_{t}=\eta_{t} y_{t}
$$

we may look at the growth consequences of this fraction. Substituting (16) into (8) gives

$$
y_{t}=A^{1 / \alpha} \frac{k_{t}}{1+n} \eta_{t}^{(1-\alpha) / \alpha}
$$

Using (10) and (7) and (17) we have

$$
\frac{k_{t+1}}{k_{t}}=\tilde{A} \frac{1-\tau_{t}^{l}}{1+n} \eta_{t}^{(1-\alpha) / \alpha}
$$

where $\tilde{A} \equiv \beta(1-\alpha) A^{1 / \alpha}(1+\beta)^{-1}$.

We see from (18) that a lower labour tax gives rise to a higher growth rate. The reason is that the young save more. Furthermore the growth rate is increasing in the level of the public production factor, $z_{t}$. However, it is costly to provide this factor, and its productively efficient level is reached when $z_{t}=(1-\alpha) y_{t}$, i.e. when $\eta_{t}=1-\alpha$. It will turn out that under the benchmark constitution production efficiency always hold.

\section{POLITICAL INSTITUTIONS}

\subsection{Political Rules}

We view political institutions as rules under which policy decisions are taken. We now outline two set of rules: The bench-mark constitution (where all policy decisions are taken in parliament) and Separation of Powers (where the spending decision is taken by a 'spending minister', and the other policies in the parliament).

The sequence of events under the bench-mark constitution is as follows: 
1. Entry of parties (individuals can register parties containing members of their own type only).

2. Electorate vote (each individual casting one vote on a party of her choice), and parties are represented proportionally to the number of votes.

3. Coalition formation in parliament (largest party chooses coalition partner, rationally anticipating the bargaining outcome). Coalition partner can only be chosen once.

4. Bargaining in the coalition takes place (with threat points of parliament dissolving for one period).

5. Tax and spending policy chosen by the majority coalition is implemented.

For separation of powers we modify the sequence of events as follows:

1. Entry of parties.

2. Electorate vote (still proportional representation).

3. Spending minister is chosen (through a vote in parliament).

4. Coalition formation in parliament.

5. Bargaining in the coalition (over the taxes).

6. Tax policy chosen by the majority coalition is implemented.

7. Spending minister decides on composition of spending.

Once individuals have been elected for parliament, they have to form a group and present a policy proposal supported by more than one half of the elected members. Contrary to the legislative bargaining literature, were a chosen legislator makes a take-it-or-leave-it proposal, we assume that both sides have a say. We model this as a simple bargaining game. The largest party can make a policy proposal. If not accepted by the coalition partner, a person 
in the coalition is chosen randomly to make a final policy proposal. If accepted it is implemented, otherwise no more offers can be made. This simple bargaining game brings a link between relative size in the coalition (the number of seats in parliament) and the equilibrium policy proposal. The larger a party is, the higher is the probability that it would be chosen in the final stage to give the final offer. This lowers smaller party's expected utility of continuing into the second stage. Therefore it would accept a (to them) less favourable proposal than otherwise. Consequently a larger party gets a policy proposal (accepted in the first stage) closer to its ideal point.

A political equilibrium is defined as follows:

(i) Given any voting outcome, and thereby given any composition of parties in parliament, the largest party must find the choice of coalition partner(s) optimal, rationally anticipating the equilibrium to the bargaining game, for each possible coalition that contains a majority of members of parliament.

(ii) Given the parties that have chosen to run for election, and rationally anticipating the coalition to form, an individual must find her choice of party to vote for optimal, given everybody else's vote, knowing that she marginally affect the bargaining outcome by marginally changing the size of the parties. $^{7}$

(iii) Members of a party (that is a group of people of the same type) must find the entry decision (that is run or not to run for election) optimal, given the other three parties entry decisions. ${ }^{8,9}$

(i), (ii), and (iii) must be mutually consistent.

\footnotetext{
7 An equilibrium to the voting game is a Nash equilibrium.

8 An equilibrium to the entry game is a Nash equilibrium.

9 In explicitly considering an entry stage, we borrow from the citizen-candidate literature (Besley and Coate (1997), Osborne and Slivinski (1996)).
} 
The equilibrium concept tells us how to solve for the political equilibria. First we characterise the bargaining outcome between various parties. Next we examine which coalitions can form. Given each possible coalition we check whether it is consistent with a Nash equilibrium in the voting game, where voters anticipate the coalition to form. Finally we check whether the entry decisions constitute a Nash equilibrium in the entry game.

In the two dimensional model (age and taste heterogeneity) there are two kinds of equilibria (which one occurs depend on the underlying parameter values). One type of equilibrium is when a single party has majority and does not have to form a coalition at all. This happens when the difference in the taste parameter is small so that the model is close to one dimensional (only age heterogeneity becomes relevant). Then if the young (old) are the largest age group, they will also have single majority in parliament. Policy then becomes the ideal point of one individual and effectively collapses to the median-voter model. These equilibria are of less interest for conducting constitutional experiments. We ill instead in this paper focus on the coalition equilibria (when no single party has majority). This involves restrictions on the underlying parameters of the model (see Renström 2002).

A particular feature of the model is that the only coalitions that can form (consistent with rational voting) is across preferences and across age. We will therefore only examine the bargaining allocations for those coalitions.

A further feature is that the coalitional equilibrium policy is a compromise (on the contract curve between two individuals). The voters of the same types as the coalition partners have a dominant strategy to vote on themselves (to pull the compromise closer the their ideal points). This implies that one of the groups that are not represented in the coalition must, in 
equilibrium, be indifferent in altering the relative coalition size. We call this group the pivotal voter. If the pivotal group was not indifferent, they would vote on their own age group (as everybody else) and the largest age group would have single majority and the coalition would not be formed. It is necessary that one group is indifferent in altering the relative coalition size (and will vote in mixed strategies), i.e. it is necessary that the pivotal voter exist.

We will proceed as follows. First solving for the bargaining allocation as function of the relative coalition size. Then finding the relative coalition size that maximises the utility of the individual group not represented in the coalition (i.e. the pivotal voter). This pins down the equilibrium.

\subsection{The Bargaining Game under Benchmark Constitution}

We will only consider equilibrium coalitions. Those are between young and old, and where young and old differ in their preferences over the environment.

Let the young group have public-goods preferences $\theta^{i}$, and the old $\theta^{j}$. Let the relative size of the young in the coalition be $\rho$, and the consequently the old's relative size is $1-\rho$. The default options are specified as the utilities if the parliament is dissolved, and consequently there are no public goods, nor taxes in that period (this gives zero utility for both).

A young individual must realise that the current wage tax will affect the savings, and hence the capital stock in the next period. This will potentially affect the next period's political-equilibrium policies: $\tau_{t+1}^{k}, g_{t+1}$, and $z_{t+1}$. We have to treat these as functions of $k_{t+1}$. We guess those functional forms, then solve the bargaining game, and lastly verify that the guesses were correct. It turns out that the tax rates themselves are independent of the capital stock. The ratios $g_{t+1} / y_{t+1}$ and $z_{t+1} / y_{t+1}$ are also independent of the capital stock $k_{t+1}$. Since $z_{t+1} / y_{t+1}$ cannot be affected by actions by the present coalition, then $R_{t+1}$ cannot be affected 
either. Consequently the after-tax return on capital, $P_{t+1}$, is taken as given by the time- $t$ coalition. The young then only have to predict how $g_{t+1}$, is affected by the coalition's actions. $g_{t+1}$ is a constant fraction of $y_{t+1}$, and $y_{t+1}$ is linear in $k_{t+1}$, which in turn is linear in $\omega_{t}$ $=(1-\alpha)\left(1-\tau_{t}^{l}\right) y_{t}$. Therefore, we may write a young individual's indirect utility as

$$
V^{i t}=\left(\left(1-\tau_{t}^{l}\right) y_{t}\right)^{1+\beta\left(1+\epsilon^{i}\right)}\left(g_{t}\right)^{e^{i}}
$$

up to a multiplicative constant.

Next, by using (6) we may write an old individual's indirect utility as

$$
V^{j t-1}=\left(\left(1-\tau_{t}^{k}\right) y_{t}\right)^{\beta}\left(g_{t}\right)^{\beta e^{j}}
$$

\subsubsection{Old the largest party}

If the old gives the final proposal, then it is optimal to set $\tau_{t}^{l}=1$, consequently $V^{i t}\left(X_{2}^{j}\right)=0$. If the young gives the final proposal, the young chooses the labour tax and the public production factor maximising own utility (19): This gives the following policy proposal (see Appendix A):

$$
\begin{array}{lll}
\hat{\tau}_{t}^{k}=1 & (21) & 1-\hat{\tau}^{l}=\frac{\alpha}{1-\alpha} \frac{1+\beta\left(1+\epsilon^{i}\right)}{(1+\beta)\left(1+\epsilon^{i}\right)} \\
\hat{z}_{t}=(1-\alpha) \hat{y}_{t} & \text { (23) } & \hat{g}_{t}=\frac{\alpha \epsilon^{i} \hat{y}_{t}}{(1+\beta)\left(1+\epsilon^{i}\right)}
\end{array}
$$

The probability that the young can implement this policy is the probability that they can make the final proposal. This probability is their relative size in the coalition, $\rho$. The young would then accept any proposal by the old in stage 1 that satisfies 


$$
\left[\left(1-\tau_{t}^{l}\right) y_{t}\right]^{1+\beta\left(1+\varepsilon^{i}\right)} g_{t}^{e^{i}} \geq \delta \rho\left[\left(1-\hat{\tau}^{l}\right) \hat{y}_{t}\right]^{1+\beta\left(1+\epsilon^{i}\right)} \hat{g}_{t}^{\mathrm{e}^{i}}
$$

The old maximises (20) subject to (25), yielding

Lemma 1 Assume A1-A6, and that all policy decisions are taken in the coalition, and that the coalition consists of old with $\varepsilon^{h}$ and young with $\varepsilon^{l}=0$, old being the largest party. Then the bargaining equilibrium is

$$
\begin{array}{ll}
1-\tau^{k}=\frac{1-[\delta \rho]^{1 /(1+\beta)}}{1+\epsilon^{j}} & 1-\tau^{l}=\frac{\alpha}{1-\alpha}[\delta \rho]^{1 /(1+\beta)} \\
z_{t}=(1-\alpha) y_{t} & \text { (26) }
\end{array}
$$

Proof: See Appendix A.

\subsubsection{Young the largest party}

If the young gives the final proposal, then it is optimal to set $\tau_{t}^{k}=1$, consequently $V^{j t-1}\left(X_{2}^{i}\right)=0$. If the old gives the final proposal, then the old chooses the capital tax and the public production factor maximising own utility (20): This gives the following policy proposal (see Appendix A):

$$
\begin{array}{lll}
1-\hat{\tau}^{k}=\frac{1}{1+\mathrm{e}^{j}} & \text { (30) } & \hat{\tau}^{l}=1 \\
\hat{z}_{t}=(1-\alpha) \hat{y}_{t} & \text { (32) } & \hat{g}_{t}=\frac{\mathrm{e}^{j} \alpha \hat{y}_{t}}{1+\mathrm{e}^{j}}
\end{array}
$$


The probability that the old can implement this policy is the probability that they can make the final proposal. This probability is their relative size in the coalition, 1- $\rho$. The old would then accept any proposal by the young in stage 1 that satisfies

$$
\left[\left(1-\tau_{t}^{k}\right) y_{t}\right]^{\beta} g_{t}^{\beta \mathrm{e}^{j}} \geq \delta(1-\rho)\left[\left(1-\hat{\tau}^{k}\right) \hat{y}_{t}\right]^{\beta} \hat{g}_{t}^{\beta \mathrm{e}^{j}}
$$

The young maximises (19) subject to (34), yielding

Lemma 2 Assume A1-A6, and that all policy decisions are taken in the coalition, and that the coalition consists of young with $\varepsilon^{h}$ and old with $\varepsilon^{l}=0$, young being the largest party. Then the bargaining equilibrium is

$$
1-\tau^{k}=[\delta(1-\rho)]^{1 / \beta}
$$

$$
z_{t}=(1-\alpha) y_{t}
$$

$$
1-\tau^{l}=\frac{\alpha}{1-\alpha} \frac{1+\beta\left(1+\epsilon^{i}\right)}{(1+\beta)\left(1+\epsilon^{i}\right)}\left[1-[\delta(1-\rho)]^{1 / \beta}\right]
$$

Proof: See Appendix A.

The solutions in Lemma 1-2 give linear sharing rules (after tax incomes are linear fractions of GDP). This is intuitive because of the Cobb-Douglas utility specification. The share depends on a group's relative size in the bargaining game. Equations (26)-(27) and (35)-(36) give the tax rates applied to the two generations. It is rather obvious that the larger the young are in relation to the old (i.e. the larger $\rho$ ) the lower will the labour tax be. The opposite for the capital tax. 
The provision of $z_{t}$, in the bench-mark constitution is according to the production-efficiency level (a constant 1- $\alpha$ of GDP). This is not surprising since Diamond-Mirrlees (1971) production efficiency holds in the second best. However, when the spending decision cannot be taken in the coalition, there is a potential deviation from production efficiency. The reason is that the coalition is deprived of one instrument (i.e. the spending proportion between the public good and the public production factor). It will turn out that there is production inefficiency under separation of powers. The reason is that the spending minister uses the spends too little on the public production factor in order to provide more of the public good. The coalition counteracts by taxing less. Furthermore, the pivotal voter will try to partially unto this effect (but not totally) by voting strategically.

\subsection{Pivotal Voter}

We will now identify the pivotal voter, i.e. the group outside the coalition that is indifferent (in equilibrium) in altering the relative coalition size. This group is picking their most preferred point on the contract curve between the two coalition partners. If a pivotal voter did not exist, it would imply that agents vote on their own age group, and the largest age group would have majority without forming the coalition. Thus, the pivotal voter is necessary for a coalitional equilibrium.

Proposition 1 Assume A1-A6, and that a group consisting of young i-types form a coalition with a group consisting of old j-types, then individuals with low preference for public goods that are not included in the coalition, vote for the individual in the coalition of their own age group. The pivotal voter is young (old) with high preference for public goods if i-types have low (high) preference, and j-types high (low) preference. 
Proof: An individual with no preference for public goods only has preference over the tax she faces. This individual finds it optimal to support its own age group since this lowers the tax rate. The only group that can be indifferent is the one excluded from the coalition and cares more for the public good. By voting mixed this group is trading off voting for opposite age group to increase public goods provision and voting for own age group to reduce the tax.

If preferences over public goods are distant enough then we have a situation where the young (or old) outside the coalition may or may not favour their own age group in the coalition. For example if $\varepsilon^{h}$ is sufficiently larger than $\varepsilon^{l}$, then there is an ideal relative coalition size (between young $\varepsilon^{l}$ and old $\varepsilon^{h}$ ) preferred by the young $\varepsilon^{h}$ outside the coalition (i.e. the pivotal voter). Thus, if such a coalition were to form the young $\varepsilon^{h}$ have no incentive to try to maximise the size of the young $\varepsilon^{l}$ or of the old $\varepsilon^{h}$. In fact, there is a relative coalition size which makes the outside group indifferent in altering the relative powers of the partners inside the coalition. Similarly, there is an ideal relative coalition size (between young $\varepsilon^{h}$ and old $\varepsilon^{l}$ ) preferred by the old $\varepsilon^{h}$ (pivotal) outside the coalition.

If $\varepsilon^{h}$ and $\varepsilon^{l}$ are too close, then any individual outside the coalition will prefer to increase the size of their own age group. The political equilibrium then reduces to a medianvoter equilibrium, with the largest age group dictating policy (and consequently confiscating from the minority age group). This is plausible since when one dimension of heterogeneity disappears $(\varepsilon)$, there is only one dimension left (age), and with one dimensional heterogeneity, logically, the model should collapse to a median-voter model. 


\subsection{Coalition Equilibrium}

Proposition 2 Assume A1-A6, and that population growth is positive. Then the coalitional equilibrium is characterised by a coalition of young $\varepsilon^{l}$ and old $\varepsilon^{h}$.

Three parties enter: young $\varepsilon^{l}$, young $\varepsilon^{h}$, and old $\varepsilon^{h}$. All old individuals vote for old $\varepsilon^{h}$. The pivotal voter is young with $\varepsilon^{h}$ and vote in mixed strategies on the three parties, being indifferent altering the relative coalition size. Equilibrium policy is

$$
\begin{array}{ll}
1-\tau^{k}=\frac{e^{h}}{(1+\beta)\left(1+\epsilon^{h}\right)^{2}} & (39) \\
z_{t}=(1-\alpha) y_{t} & g_{t}=\frac{\left(\epsilon^{h}\right)^{2} \alpha y_{t}}{(1+\beta)\left(1+\epsilon^{h}\right)^{2}}
\end{array}
$$

Proof: Suppose there was a coalition across age groups but with same public-goods preferences. Then all agents have an incentive to vote on their own age group. Then the young $\varepsilon^{i}$ would have majority and the coalition would not form, which is a contradiction. The same argument hold for coalitions within age groups. Finally consider the mirror image of the coalition above: old $\varepsilon^{l}$ and young $\varepsilon^{h}$. Then by proposition 2 the pivotal voter is old, implying that all young vote young $\varepsilon^{h}$. But then the young $\varepsilon^{h}$ obtain majority without forming the coalition. The coalition above is the only one consistent with rational voting when $n>0$. The pivotal young with $\varepsilon^{h}$ maximises (19) with respect to the vote share, giving

$$
\rho=\frac{1}{\delta}\left[\frac{1+\beta\left(1+\epsilon^{h}\right)}{(1+\beta)\left(1+\epsilon^{h}\right)}\right]^{1+\beta}
$$

Substituting (43) into Lemma 1 gives (39)-(42). 
Proposition 3 Assume A1-A6, and that population growth is negative. Then the coalitional equilibrium is characterised by a coalition of young $\varepsilon^{h}$ and old $\varepsilon^{l}$.

Three parties enter: old $\varepsilon^{l}$, old $\varepsilon^{h}$, and young $\varepsilon^{h}$. All young individuals vote for young $\varepsilon^{h}$. The pivotal voter is old with $\varepsilon^{h}$ and vote in mixed strategies on the three parties, being indifferent altering the relative coalition size. Equilibrium policy is

$$
\begin{array}{ll}
1-\tau^{k}=1 /\left(1+\epsilon^{h}\right) & 1-\tau^{l}=\frac{\alpha \epsilon^{h}}{1-\alpha} \frac{1+\beta\left(1+\epsilon^{h}\right)}{(1+\beta)\left(1+\epsilon^{h}\right)^{2}} \\
z_{t}=(1-\alpha) y_{t} & \text { (46) }
\end{array}
$$

Proof: For the first part, see the proof of Proposition 2. The pivotal old with $\varepsilon^{h}$ maximises (20) with respect to the vote share, giving

$$
1-\rho=\frac{1}{\delta}\left[\frac{1}{1+\epsilon^{h}}\right]^{\beta}
$$

Substituting (48) into Lemma 2 gives (44)-(47).

Rather paradoxically, though in Proposition 2 the young are in majority (if we rank according to age) the largest party, who also is choosing coalition, consists of old. The reason is that there is a possibility that the old will get their income confiscated. By entering as one party (as old $\varepsilon^{h}$ ), all old votes are concentrated on one party. Whenever there is a possibility that young $\varepsilon^{l}$ can enter in a coalition with the old, they are better off running separately, and splitting the votes of the young. This, at the same time, makes a single young party not in majority. Though the largest party consists of old, redistribution goes from old to young. The reason is that the equilibrium is such that a young group is the pivotal voter. The same reasoning holds the other way around when population declines (Proposition 3). 


\subsection{Growth Consequences}

We can compare the per-capita growth rates under population growth (Proposition 2) and population decline (Proposition 3). Since both equilibria give rise to production efficiency $(\eta=1-\alpha)$, only the labour tax matters, see equation (18). Using (40) and (45) we see that when population growth/decline differs slightly from zero, the equilibrium in Proposition 2 gives a higher growth rate. The reason is that the pivotal voter is young when population grows, and the pivotal voter has considerable power in picking her most preferred point on the contract curve between the coalition partners. This gives a lower labour tax, which in turn increases savings and growth.

\section{SEPARATION OF POWERS}

\subsection{Election or Appointment of Spending Minister}

We will now analyze a situation when the tax decision is taken in parliament and the spending decision is taken by an elected or appointed decision maker (spending minister). We consider election in parliament and appointment by the largest party in parliament. ${ }^{10}$

Proposition 4 Assume A1-A6. If population growth is positive (negative), then the majority elected (in parliament) spending minister is young (old) with high preferences for the public good, that is, of the same type as the pivotal voter.

Proof: The spending minister coincides with the median in parliament.

10 Potentially we can consider many constitutional experiments. For example, the tax authority could be appointed/elected. Alternatively, one can consider two legislatures (two-chamber parliament). We leave these experiments for future research. 
Proposition 5 Assume A1-A6. If population growth is positive (negative), then the appointed (by the largest party) spending minister is old (young) with high preferences for the public good, that is, of the same type as the largest party.

Proof: The largest party has an incentive to pick a spending minister of the same type.

In either case, the minister is of type $\varepsilon^{h}$ (either median in parliament or same as the largest party). The objective is either (19) or (20) depending on age. However, because the tax rates are taken as given, we can consider the following objective

$$
\ln V^{m}=\ln y_{t}+e^{m} \ln g_{t}=\ln y_{t}+e^{m} \ln \left(\pi_{t} y_{t}-z_{t}\right)
$$

where the latter equality follows from (14), and where

$$
e^{m}=\left\{\begin{array}{c}
\epsilon^{h} /\left[1+\beta\left(1+\epsilon^{h}\right)\right] \text { if young } \\
e^{h} \text { if old }
\end{array}\right.
$$

Maximising with respect to $z_{t}$ (and consequently $g_{t}$ ) gives the minister's optimal choice as functions of the tax rates (recall the definition of $\pi_{t}$ in (15)):

$$
\begin{gathered}
z_{t}=\frac{(1-\alpha)\left(1+\epsilon^{m}\right)}{1-\alpha+\epsilon^{m}} \pi_{t} y_{t} \\
g_{t}=\frac{\alpha \epsilon^{m}}{1-\alpha+\epsilon^{m}} \pi_{t} y_{t}
\end{gathered}
$$

\subsection{The Bargaining Game under Separation of Powers}

\subsubsection{Old the largest party}


Lemma 3 Assume A1-A6, and that only the tax decisions is taken in the coalition (separation of powers), and that the coalition consists of old with $\varepsilon^{h}$ and young with $\varepsilon^{l}=0$, old being the largest party. Then the bargaining equilibrium is

$$
\begin{gathered}
\tau_{t}^{k}=\frac{\mathrm{e}^{j}}{1+\mathrm{e}^{j}}+\frac{1-\alpha}{\alpha} \frac{1-\tau_{t}^{l}}{1+\mathrm{e}^{j}} \\
\left(1-\tau_{t}^{l}\right)\left[\frac{1+\frac{\mathrm{e}^{j}}{1-\alpha}-\mathrm{e}^{j}\left(1-\tau_{t}^{l}\right)}{1+\mathrm{e}^{j}}\right]^{(1-\alpha) / \alpha}=[\delta \rho]^{1 /(1+\beta)} \frac{\alpha}{1-\alpha}
\end{gathered}
$$

Proof: See Appendix B.

Corollary 1 Assume A1-A6, and that the coalition consists of old with $\varepsilon^{h}$ and young with $\varepsilon^{l}=0$, old being the largest party. Then, given the relative coalition size $(\rho)$, the labour tax is higher under separation of powers than under the benchmark.

Proof: Follows by comparing (54) and (27). Notice that the bracketed term in (54) is greater than unity.

The reason is that the old can get a higher labour tax accepted by the young because the spending minister tend to spend too little on the public production factor (lower that the productively efficient level). The young then accepts a higher labour tax because it will increase the public production factor.

\subsubsection{Young the largest party}


Lemma 4 Assume A1-A6, and that only the tax decisions is taken in the coalition (separation of powers), and that the coalition consists of young with $\varepsilon^{h}$ and old with $\varepsilon^{l}=0$, young being the largest party. Then the bargaining equilibrium is

$$
\begin{gathered}
1-\tau_{t}^{l}=\frac{\alpha}{1-\alpha} \frac{1+\beta\left(1+\epsilon^{i}\right)}{(1+\beta)\left(1+\epsilon^{i}\right)} \tau_{t}^{k} \\
\left(1-\tau_{t}^{k}\right)\left[1+\frac{\alpha \epsilon^{i} /(1-\alpha)}{(1+\beta)\left(1+\epsilon^{i}\right)} \tau_{t}^{k}\right]^{(1-\alpha) / \alpha}=[\delta(1-\rho)]^{1 / \beta}
\end{gathered}
$$

Proof: See Appendix B.

Corollary 2 Assume A1-A6, and that the coalition consists of young with $\varepsilon^{h}$ and old with $\varepsilon^{l}=0$, young being the largest party. Then, given the relative coalition size $(\rho)$, the capital tax is higher under separation of powers than under the benchmark.

Proof: Follows by comparing (56) and (35). Notice that the bracketed term in (56) is greater than unity.

QED

The reason is the same as for Corollary 1, i.e. the young can get a higher capital tax accepted by the old because the spending minister tend to spend too little on the public production factor. The old then accepts a higher capital tax because it will increase the public production factor.

\subsection{Pivotal Voter}

Proposition 1 holds here as well. The identity of the pivotal voter does not change. 


\subsection{Coalition Equilibrium}

Proposition 6 Assume A1-A6, separation of powers, and that population growth is positive. Then the coalitional equilibrium is characterised by a coalition of young $\varepsilon^{l}$ and old $\varepsilon^{h}$.

Three parties enter: young $\varepsilon^{l}$, young $\varepsilon^{h}$, and old $\varepsilon^{h}$. All old individuals vote for old $\varepsilon^{h}$. The pivotal voter is young with $\varepsilon^{h}$ and vote in mixed strategies on the three parties, being indifferent altering the relative coalition size. Equilibrium tax policy is

$$
1-\tau^{k}=\frac{e^{h}}{(1+\beta)\left(1+e^{h}\right)^{2}}\left[1-\frac{1-\alpha}{e^{h}} \frac{1+\beta\left(1+\epsilon^{h}\right)}{e^{h}}\right] \text { (57) } \quad 1-\tau^{l}=\frac{\alpha}{1-\alpha} \frac{1+\beta\left(1+\epsilon^{h}\right)}{(1+\beta)\left(1+e^{h}\right)}\left[1+\frac{1-\alpha}{\epsilon^{h}}\right]
$$

Proof: The first part is proven in the same way as the first part of Proposition 2. The pivotal young with $\varepsilon^{h}$ maximises (19) with respect to the vote share. This can be reformulated as maximising (19) with respect to the labour tax, i.e. $\max \left[1+\beta\left(1+\varepsilon^{i}\right)\right] \ln \left[\left(1-\tau_{t}^{l}\right) y_{t}\right]+\varepsilon^{i} \ln \left(\pi_{t}-z_{t}\right)$, or equivalently to

$$
\max _{\tau_{t}^{l}}\left[1+\beta\left(1+\epsilon^{i}\right)\right] \ln \left(1-\tau_{t}^{l}\right)+\left[(1+\beta)\left(1+\epsilon^{i}\right) \frac{1-\alpha}{\alpha}+\epsilon^{i}\right] \ln \pi_{t}
$$

subject to (15) and (53). The first-order condition gives (57) and (58).

QED

Notice that the tax policy is independent of the identity of the spending minister.

Corollary 3 Assume A1-A6, and that population growth is positive. Then the capital (labour) tax is larger (smaller) under separation of powers than under the benchmark constitution. The size of the young in the coalition is also larger under separation of powers. 
Proof: Follows by comparing (57) and (58) with (39) and (40), respectively. The coalition size follows from Corollary 1 . To obtain a lower labour tax the relative coalition size must be larger.

QED

Corollary 3 shows that the pivotal voter counteracts the effect of separation of powers, by increasing the vote share to the young.

Proposition 7 Assume A1-A6, and that population growth is negative. Then the coalitional equilibrium is characterised by a coalition of young $\varepsilon^{h}$ and old $\varepsilon^{l}$.

Three parties enter: old $\varepsilon^{l}$, old $\varepsilon^{h}$, and young $\varepsilon^{h}$. All young individuals vote for young $\varepsilon^{h}$. The pivotal voter is old with $\varepsilon^{h}$ and vote in mixed strategies on the three parties, being indifferent altering the relative coalition size. Equilibrium tax policy is

$$
1-\tau^{k}=\frac{1}{1+\epsilon^{h}}+\frac{1-\alpha}{\epsilon^{h}} \frac{1+\beta\left(1+\epsilon^{h}\right)}{1+\epsilon^{h}} \text { (60) } 1-\tau^{l}=\frac{\alpha \epsilon^{h}}{1-\alpha} \frac{1+\beta\left(1+\epsilon^{h}\right)}{(1+\beta)\left(1+\epsilon^{h}\right)^{2}}\left[1-\frac{1-\alpha}{\epsilon^{h}} \frac{1+\beta\left(1+\epsilon^{h}\right)}{\epsilon^{h}}\right]
$$

Proof: For the first part, see the proof of Proposition 2. The pivotal old with $\varepsilon^{h}$ maximises (20) with respect to the vote share. This can be reformulated as maximising (20) with respect to the capital tax, i.e. $\max \ln \left[\left(1-\tau_{t}^{k}\right) y_{t}\right]+\varepsilon^{j} \ln \left(\pi_{t}-z_{t}\right)$, or equivalently to

$$
\max _{\substack{\tau_{t}^{k} \\ \tau^{k}}} \ln \left(1-\tau_{t}^{k}\right)+\frac{1-\alpha+\mathrm{e}^{j}}{\alpha} \ln \pi_{t}
$$

subject to (15) and (55). The first-order condition gives (60) and (61).

QED

Also here the tax policy is independent of the identity of the spending minister. 
Corollary 4 Assume A1-A6, and that population growth is negative. Then the capital (labour) tax is smaller (larger) under separation of powers than under the benchmark constitution. The size of the old in the coalition is also larger under separation of powers.

Proof: Follows by comparing (60) and (61) with (44) and (45), respectively. The coalition size follows from Corollary 2. To obtain a lower capital tax, old's relative coalition size must be larger.

QED

Corollary 4 shows that the pivotal voter counteracts the effect of separation of powers, by increasing the vote share to the old.

Finally, the spending decision depends on the identity of the spending minister. However, the decision is independent of whether population is growing or declining. We have

Proposition 8 Assume A1-A6, and separation of powers. Then in the coalitional equilibrium, the spending decision is independent of whether $n>0$ or $n<0$, and is given by

$$
z_{t}=\frac{(1-\alpha)\left(1+\epsilon^{m}\right)}{1-\alpha+\epsilon^{m}} \pi y_{t} \quad \text { (63) } \quad g_{t}=\left[1-\frac{(1-\alpha)\left(1+\epsilon^{m}\right)}{1-\alpha+\epsilon^{m}}\right] \pi y_{t}
$$

where

$$
\pi=1-\alpha+\frac{\alpha}{1+\beta}\left(\frac{\epsilon^{h}}{1+e^{h}}\right)^{2}-\frac{\alpha}{1+\beta} \frac{1-\alpha}{1+e^{h}} \frac{1+\beta\left(1+\epsilon^{h}\right)}{1+e^{h}}
$$

Proof: (65) follows by substituting (57)-(58) and (60)-(61) into (15). (63) and (64) are restatements of (51) and (52). 
Corollary 5 Assume A1-A6, and separation of powers. Then in the coalitional equilibrium the public production factor is supplied at a lower level than the productively efficient one.

Proof: It follows by (63) and (65) that $z_{t}<(1-\alpha) y_{t}$.

The production inefficiency is due to the fact that the spending minister tries to obtain a higher level of the public good than the coalition wishes. The coalition tries to (partially but not fully) counter this by increasing the taxes. The productively inefficient level of $z_{t}$ tends to lower the growth rate, however, we must evaluate the total effect, also taking into account the taxes. This is done in the next section.

\section{GROWTH CONSEQUENCES OF CONSTITUTIONS}

\subsection{Elected versus appointed spending minister}

Given separation of powers, $\pi$ is independent of the identity of the spending minister. Then according to (51) the growth rate is decreasing in $\varepsilon^{m}$. Then (50) implies that under a young spending minister growth is greater (other things equal). Thus we have the following

Proposition 9 Assume A1-A6, and separation of powers, then in the coalitional equilibrium, the following is true

(i) If $n>0$ economic growth is greater under elected than appointed spending minister.

(ii) If $n<0$ economic growth is smaller under elected than under appointed spending minister.

(iii) Highest growth is obtained when $n>0$ and spending minister is elected and lowest growth is obtained when $n<0$ and spending minister is elected. 
Proof: (i) and (ii) follow from Proposition 4-5.(iii) follows since the labour tax is smaller when $\mathrm{n}>0$ than when $\mathrm{n}<0$.

In evaluating the growth consequences, population growth becomes critical. The reason is that the identity of the spending minister depends on which age group is in majority in the population.

\subsection{Benchmark versus separation of powers}

Proposition 10 Assume A1-A6, then in the coalitional equilibrium, the following is true

(i) If $n<0$ economic growth is greater under the benchmark than under separation of powers.

(ii) Economic growth is greater under separation of powers when $n>0$ than under the benchmark when $n<0$.

(iii) If $n>0$ economic growth can be greater or smaller under the benchmark.

Proof: (i) Corollary 5 gives $z_{t}<(1-\alpha) y_{t}$. Corollary 4 states that the labour tax is greater under separation of powers. Thus, the lowest growth rate is obtained under separation of powers when $\mathrm{n}<0$.

(ii) Substituting (45) and (46) into (18) and comparing to when (58), (63), and (65) are substituted into (18) establishes that growth is greater when $\mathrm{n}>0$ and there is separation of powers than when $\mathrm{n}<0$ and the benchmark constitution holds.

(iii) Follows by substituting (40) and (41) into (18) and comparing to when (58), (63), and (65) are substituted into (18).

QED 


\section{CONCLUSIONS}

The paper develops a political-economy model to analyse whether decisions upon government spending should be taken by a parliament or an independent decision maker.

The underlying economy is an overlapping-generations economy, where individuals differ in preferences over a public good (as well as in age). Labour- and capital taxes are used to finance public goods provision, period by period, as well as a public production factor. Economic growth is generated by the public production factor.

As a contribution to the literature, we have carefully modelled a political system (parliament) and underlined the consequences for economic growth of changing constitutions. The legislature is modelled as a parliament. Individuals may form parties, and the electorate vote on the parties that have decided to run for election. The number of seats obtained by a party in parliament is proportional to the number of votes it gets. Given the election result parties form coalitions to bargain over policy proposals. The implemented proposal is the one getting more than half of the votes in parliament.

We have compared two constitutions: (I) a bench-mark case where all policy decisions are taken in parliament, (II) separation of powers, where either the parliament elects or the largest party appoints a spending minister, who in turn sets spending policy independently.

The way in which equilibrium coalitions are formed is the key in understanding how growth is influenced. When there is population growth, so that the young are the largest age group, the young split in two parties (and the old enter as one party). The young party with high preferences for public goods will be excluded from the coalition, but has to be indifferent in altering the relative coalition size of the equilibrium coalition. This gives considerable power to the group outside the coalition, who in effect will influence policy the most. Since a young group is the most influential group policy will favour this group. The young have a stronger incentive to spend on the public production factor, which will increase equilibrium savings and consumption possibilities in the next period. Consequently economic growth is higher in this equilibrium. On the contrary, if population growth is negative, the old 
will split into two parties, and a sub-group of the old will be excluded from the coalition but will have strong influence (when determining relative coalition size). Since the old are more influential equilibrium growth will be lower. We also considered a modified constitution: separation of powers.

In the first modified constitution the largest party has the right to appoint an individual who will take the spending decision. When population growth is positive, the largest party consists of old, and therefore the spending decision maker will be an old individual. However, this individual will choose to spend less on the public production factor than the parliament would have chosen. Similarly when population growth is negative, the largest party (who are young) will appoint a young decision maker. Comparing effect of constitutions here is ambiguous. The reason is that separation of powers gives a lower wage tax (which works positively for growth) but at the same time the public production factor is supplied plbelow the productively efficient level (and thus lowering growth).

In the second modified constitution the spending decision maker is majority elected in parliament. Here the elected decision maker will always be of the same age group as the dominant age group (i.e. if population growth is positive, the elected decision maker is young, and vice versa). To conclude:

\section{Table 1 - Level of Economic Growth}

\begin{tabular}{|c|c|c|c|}
\hline & $\underline{\text { separat }}$ & powers & decision in \\
\hline & elected & appointed & \\
\hline pop. growth $>0$ & highest & second highest & high or highest \\
\hline pop. growth $<0$ & lowest & second lowest & high \\
\hline
\end{tabular}

This suggests that societies in choosing the constitution should take into account the expected population growth. We may offer an alternative interpretation. ${ }^{11}$ Instead of emphasising demographic characteristics we could have emphasised the distribution of factor ownership. Growth is generally higher when wage earners are the largest group, and higher when the spending minister is a wage earner.

\footnotetext{
11 We thank Piergiuseppe Fortunato for suggesting this interpretation.
} 


\section{REFERENCES}

Acemoglu, Daron, Johnson, Simon, and Robinson, James (2001), "The Colonial Origins of Comparative Development: An Empirical Investigation", American Economic Review 91:1369-1401.

Acemoglu, Daron, Johnson, Simon, and Robinson, James (2004), "Institutions as the Fundamental Cause of Long-Run Growth", NBER Working Paper, No.10481.

Banks, Jeffrey S., and John Duggan (2000), "A Multidimensional Model of Repeated Elections," Wallis Institute of Political Economy Working Paper no. 24, University of Rochester.

Baron, David, and John Ferejohn (1989), "Bargaining in Legislatures," American Political Science Review 83:1181-1206.

Besley, Timothy, and Stephen Coate (1997), "An Economic Model of Representative Democracy," Quarterly Journal of Economics 112:85-106.

Diamond, Peter, A., and James A. Mirrlees (1971), "Optimal Taxation and Public Production I: Production Efficiency," American Economic Review 61:1-29.

Glaeser, Ed, La Porta, Rafael, Lopez de Silanes, Florencio, and Shleifer, Andrei (2004), "Do Institutions Cause Growth?", NBER Working Paper, No. 10568.

Hall, Robert, and Jones, Chad (1999), "Why Do Some Country Produce so Much More Output Per Worker than Others?", Quarterly Journal of Economics 114:83-116.

Lizzeri, Alessandro, and Persico Nicola (2001), "The Provision of Public Goods under Alternative Electoral Incentives", American Economic Review 91:225-245.

Milesi-Feretti, Gian-Maria, Perotti, Roberto, and Rostagno, Marco (2002), "Electoral Systems and the Composition of Government Spending", Quarterly Journal of Economics 117:609-657.

Osborne, Martin J., and Al Slivinski (1996), "A Model of Political Competition with Citizen-Candidates," Quarterly Journal of Economics 111:65-96.

Persson, Torsten (2004), "Forms of Democracy, Policy and Economic Development", mimeo, Stockholm University.

Persson, Torsten, Gerard Roland, and Guido Tabellini (1998), "Towards Micropolitical Foundations of Public Finance," European Economic Review 42(3-5):685-694.

Persson, Torsten, Gerard Roland, and Guido Tabellini (2000), "Comparative Politics and Public Finance," Journal of Political Economy 108:1121-1161. 
Persson, Torsten, Gerard Roland, and Guido Tabellini (2003), "How Do Electoral Rules Shape Party Structure, Government Coalitions and Economic Policies?" mimeo, Stockholm University.

Persson, Torsten, and Guido Tabellini (1994a), "Is Inequality Harmful for Growth? Theory and Evidence," American Economic Review 84:600-621.

Persson, Torsten, and Guido Tabellini (1999), "The Size and Scope of Government: Comparative Politics with Rational Politicians," European Economic Review 43(4-6):699-735.

Persson, Torsten, and Guido Tabellini (2003), The Economic Effects of Constitutions, Cambridge, MA:MIT Press.

Persson, Torsten, and Guido Tabellini (2004), "Constitutional Rules and Fiscal Policy Outcome," American Economic Review 94:25-46.

Renström, Thomas I. (1996), "Endogenous Taxation: An Overlapping Generations Approach," Economic Journal 106:471-482.

Renström, Thomas I. (2002), "Political Institutions and Redistribution," in Proceedings of the 2002 North American Summer Meetings of the Econometric Society: Economic Theory, edited by D.K. Levine, W. Zame, L. Ausubel, P.A. Chiappori, B. Ellickson, A. Rubinstein and L. Samuelson. http://www.dklevine.com/proceedings/development.htm

Rodrik, Dani, Subramnian, Arvind, and Trebbi, Francesco (2004), "Institutions Rules: The Primacy of Institutions Over Geography and Integration in Economic Development", Journal of Economic Growth 9:131-166.

Turnovsky, Stepen J., and Walter H. Fisher (1995), "The Composition of Government Expenditure and its Consequences for Macroeconomic Performance," Journal of Economic Dynamics \& Control 19: 747-786. 


\section{APPENDIX A: Bargaining Game under Benchmark Constitution}

Policy proposal in the last stage

Define $m_{t}^{i} \equiv\left(1-\tau_{t}^{l}\right) y_{t}$ and $m_{t}^{j} \equiv\left(1-\tau_{t}^{k}\right) y_{t}$, then (14) and (15) give

$$
g_{t}=y_{t}-\alpha m_{t}^{j}-(1-\alpha) m_{t}^{i}-z_{t}
$$

Notice that (19) may be written as

$$
\begin{aligned}
\ln V_{t}^{i t} & =\left[1+\beta\left(1+\epsilon^{i}\right)\right] \ln \left(\left(1-\tau_{t}^{l}\right) y_{t}\right)+\epsilon^{i} \ln \left(\pi_{t} y_{t}-z_{t}\right) \\
& =\left[1+\beta\left(1+\epsilon^{i}\right)\right] \ln m_{t}+\epsilon^{i} \ln \left(y_{t}-(1-\alpha) m_{t}-z_{t}\right)
\end{aligned}
$$

The first-order conditions are

$$
\begin{gathered}
\frac{1+\beta\left(1+\epsilon^{i}\right)}{m_{t}}-\frac{\epsilon^{i}(1-\alpha)}{y_{t}-(1-\alpha) m_{t}-z_{t}}=0 \\
\frac{\partial y_{t}}{\partial z_{t}}-1=0
\end{gathered}
$$

(A4) gives (23), which substituted into (A3) gives (22). Using (21) and (22) in (A1) gives (24).

Proof of Lemma 1

Log-differentiate the constraint (25) to obtain

$$
\frac{d m_{t}^{i}}{m_{t}^{i}}+\frac{\epsilon^{i}}{1+\beta\left(1+\epsilon^{i}\right)} \frac{d g_{t}}{g_{t}}=0
$$

Taking the total differential of (A1) and using (A5) gives

$$
\left[g_{t}-\frac{(1-\alpha) \epsilon^{i} m_{t}^{i}}{1+\beta\left(1+\epsilon^{i}\right)}\right] \frac{d g_{t}}{g_{t}}=d\left(y_{t}-z_{t}\right)-\alpha d m_{t}^{j}
$$


Maximising $\ln V^{j-1}=\ln m_{t}^{j}+\varepsilon^{j} \ln g_{t}$ with respect to $m_{t}^{j}$ and $z_{t}$, using (A6), gives

$$
\frac{1}{m_{t}^{j}}-\frac{\epsilon^{j} \alpha}{g_{t}-(1-\alpha) m_{t}^{i} \epsilon^{i} /\left[1+\beta\left(1+\epsilon^{i}\right)\right]}=0
$$

and the production efficiency condition $\partial y_{t} / \partial z_{t}=1$, in turn implying (28).

The first-order condition (A7) gives

$$
g_{t}=\epsilon^{j} \alpha m_{t}^{j}+(1-\alpha) m_{t}^{i} \epsilon^{i} /\left[1+\beta\left(1+\epsilon^{i}\right)\right]
$$

which combined with (A1) gives

$$
g_{t}=\frac{\epsilon^{j} \alpha y_{t}-(1-\alpha) m_{t}^{i}\left(\epsilon^{j}-\epsilon^{i} /\left[1+\beta\left(1+\epsilon^{i}\right)\right]\right)}{1+\epsilon^{j}}
$$

First, (28) implies $y_{t}=\hat{y}_{t}$. Then (25) evaluated at $\varepsilon^{i}=0$ gives (27). (27) in (A9) gives (29). (27) and (29) in (A8) gives (26).

QED

Policy proposal in the last stage

Since $m_{t}{ }^{i}=0$, using (A1) in (20) the old's objective is to maximise $\ln V^{j t-1}=\ln m_{t}^{j}+\varepsilon^{j} \ln g_{t}$. The first-order conditions are

$$
\frac{1}{m_{t}^{j}}-\frac{e^{j} \alpha}{y_{t}-\alpha m_{t}^{j}-z_{t}}=0
$$

and the production efficiency condition $\partial y_{t} / \partial z_{t}=1$, in turn implying (32).

(32) substituted into (A10) gives (30). Using (30) and (32) in (A1) gives (33).

Proof of Lemma 2

Log-differentiate the constraint (34) to obtain

$$
\frac{d m_{t}^{j}}{m_{t}^{j}}+\mathrm{e}^{j} \frac{d g_{t}}{g_{t}}=0
$$

Taking the total differential of (A1) and using (A11) gives 


$$
\left[g_{t}-\alpha e^{j} m_{t}^{j}\right] \frac{d g_{t}}{g_{t}}=d\left(y_{t}-z_{t}\right)-(1-\alpha) d m_{t}^{i}
$$

Maximising $\ln V^{i t}=\left[1+\beta\left(1+\varepsilon^{i}\right)\right] \ln m_{t}^{i}+\varepsilon^{i} \ln g_{t}$ with respect to $m_{t}^{i}$ and $z_{t}$, using (A12), gives

$$
\frac{1+\beta\left(1+\epsilon^{i}\right)}{m_{t}^{i}}-\frac{e^{i}(1-\alpha)}{g_{t}-\alpha m_{t}^{j} e^{j}}=0
$$

and the production efficiency condition $\partial y_{t} / \partial z_{t}=1$, in turn implying (37). The first-order condition (A13) gives the same g equation (A8). Use (A1) in (A8) to eliminate $m_{t}^{i}$ to obtain

$$
g_{t}=\frac{e^{j} \alpha}{(1+\beta)\left(1+\epsilon^{i}\right)}\left[y_{t}+\left(\frac{e^{j}}{\epsilon^{i}}\left[1+\beta\left(1+\epsilon^{i}\right)\right]-1\right) m_{t}^{j}\right]
$$

Equation (37) implies $y_{t}=\hat{y}_{t}$. Then (34) evaluated at $\varepsilon^{j}=0$ gives $1-\tau_{t}^{k}=[\delta(1-\rho)]^{1 / \beta}\left(1-\hat{\tau}_{t}^{k}\right)$. Using (30) and $\varepsilon^{j}=0$ gives (35). Use (35) in (A14) to obtain (38).

QED

\section{APPENDIX B: Bargaining Game under Separation of Powers}

\section{Proof of Lemma 3}

The relation between GDP and $\pi$ from the viewpoint of the coalition is as follows

$$
\ln y_{t}=\frac{1-\alpha}{\alpha} \ln \pi_{t}+\text { constant }
$$

A young with $\varepsilon^{i}=0$ makes final offer so as to maximise $\left(1-\tau_{t}^{l}\right) y_{t}$. Since it is optimal to set $\tau_{t}^{k}=1$, then $\pi_{t}=1-(1-\alpha)\left(1-\tau_{t}^{l}\right)$ and by using (B1) the objective is to

$$
\max _{\substack{l \\ \tau_{t}}} \ln \left(1-\tau_{t}^{l}\right)+\frac{1-\alpha}{\alpha} \ln \left[1-(1-\alpha)\left(1-\tau_{t}^{l}\right)\right]
$$

The first-order condition gives $1-\hat{\tau}_{t}^{l}=\alpha /(1-\alpha)$, and consequently $\pi_{t}=1-\alpha$. The old can then offer anything that satisfies $\left[\left(1-\tau_{t}^{l}\right) y_{t}\right]^{1+\beta} \geq \delta \rho\left[\left(1-\hat{\tau}_{t}^{l}\right) \hat{y}_{t}\right]^{1+\beta}$ or

$$
\left(1-\tau_{t}^{l}\right) \pi_{t}^{(1-\alpha) / \alpha} \geq[\delta \rho]^{1 /(1+\beta)} \frac{\alpha}{1-\alpha}(1-\alpha)^{(1-\alpha) / \alpha}
$$


Old makes initial offer to maximise $\ln \left[\left(1-\tau_{t}^{k}\right) y_{t}\right]+\varepsilon^{j} \ln \left(\pi_{t}-z_{t}\right)$, or equivalently to maximise

$$
\ln \left(1-\tau_{t}^{k}\right)+\frac{1-\alpha+\mathrm{e}^{j}}{\alpha} \ln \pi_{t}
$$

subject to (B3). The first-order condition gives (53). Substitute (53) into (15) to obtain

$$
\pi_{t}=\frac{1+\mathrm{e}^{j}-\alpha-\mathrm{e}^{j}(1-\alpha)\left(1-\tau_{t}^{l}\right)}{1+\mathrm{e}^{j}}
$$

(B5) in (B3) gives (54).

QED

\section{Proof of Lemma 4}

An old with $\varepsilon^{j}=0$ makes final offer so as to maximise $\left(1-\tau_{t}^{k}\right) y_{t}$. Since it is optimal to set $\tau_{t}^{l}=1$, then $\pi_{t}=1-\alpha\left(1-\tau_{t}^{k}\right)$ and by using (B1) the objective is to

$$
\max _{\tau_{t}^{k}} \ln \left(1-\tau_{t}^{k}\right)+\frac{1-\alpha}{\alpha} \ln \left[1-\alpha\left(1-\tau_{t}^{k}\right)\right]
$$

The first-order condition gives $\hat{\tau}_{t}^{k}=0$, and consequently $\pi_{t}=1-\alpha$. The young can then offer anything that satisfies $\left[\left(1-\tau_{t}^{k}\right) y_{t}\right]^{\beta} \geq \delta(1-\rho)\left[\left(1-\hat{\tau}_{t}^{k}\right) \hat{y}_{t}\right]^{\beta}$ or

$$
\left(1-\tau_{t}^{k}\right) \pi_{t}^{(1-\alpha) / \alpha} \geq[\delta(1-\rho)]^{1 / \beta}(1-\alpha)^{(1-\alpha) / \alpha}
$$

Young makes initial offer to maximise $\left[1+\beta\left(1+\varepsilon^{i}\right)\right] \ln \left[\left(1-\tau_{t}^{l}\right) y_{t}\right]+\varepsilon^{i} \ln \left(\pi_{t}-z_{t}\right)$, or equivalently to maximise

$$
\left[1+\beta\left(1+\epsilon^{i}\right)\right] \ln \left(1-\tau_{t}^{l}\right)+\left[(1+\beta)\left(1+\epsilon^{i}\right) \frac{1-\alpha}{\alpha}+\epsilon^{i}\right] \ln \pi_{t}
$$

subject to (B7). The first-order condition gives (55). Substitute (55) into (15) to obtain

$$
\pi_{t}=1-\alpha+\frac{\alpha e^{i}}{(1+\beta)\left(1+\epsilon^{i}\right)} \tau_{t}^{k}
$$

(B5) in (B3) gives (54). 